\title{
AS COSTUREIRAS, AS QUEENS E OS SEUS MANTOS. DESTERRITORIALIZAÇÃO, CULTURA MATERIAL E CONSTRUÇÃO DO LUGAR
}

Filomena SilvanO ${ }^{1}$

\begin{abstract}
Resumo - Durante as décadas de 1980 e de 1990 a noção de lugar na literatura antropológica foi sujeita a uma abordagem crítica que debateu as dimensões metodológicas e conceptuais envolvidas na sua construção. No seguimento desse debate, surgiram propostas de trabalho que, de maneiras muito diversas, conseguiram ultrapassar as limitações das concepções mais clássicas da figura do lugar. Essas propostas revelaram, no entanto, que, mesmo quando estamos face a uma lógica de desterritorialização, a figura do lugar pode reaparecer (embora obviamente transmutada, visto construir-se no interior de outras lógicas sociais, culturais e económicas). Partindo de um estudo etnográfico realizado na Ilha do Pico, o texto explora algumas das inovações, provenientes dos EUA no início do século XX, que foram introduzidas nas Festas do Espírito Santo. A principal inovação prende-se com a emergência de novos personagens: as rainhas (queens) coroadas durante o ritual, seguidas pelas costureiras indispensáveis à confecção dos seus vestidos e mantos. Centrado nos processos de feitura dos mantos, o texto pretende mostrar como a cultura material local se constrói e se transforma no interior de um movimento transcontinental constante de pessoas, rituais, coisas e técnicas. Num contexto transnacional, a mobilidade das pessoas pode "objectificar-se" em coisas que são feitas localmente, participando assim a desterritorialização na construção do lugar.
\end{abstract}

Palavras-chave: Lugar, transnacionalismo, cultura material, festas do Espírito Santo, Ilha do Pico (Açores).

Abstract - Dressmakers, QUeens and their ClOAKs: Deterritorialization, MATERIAL CUlture AND THE CONSTRUCTION OF PLACE. In the late twentieth century, during the 1980s and 1990s, the anthropological notion of place was subject to critical revisions.

1 Filomena Silvano é Antropóloga, Professora da Faculdade de Ciências Sociais e Humanas da Universidade Nova de Lisboa (FCSH-UNL) e membro do Centro em Rede de Investigação em Antropologia (CRIA). No seu trabalho relaciona as questões das identidades colectivas e individuais com o estudo do espaço, do habitat, da cultura material e da cultura expressiva. É autora dos livros "Territórios da Identidade", "Antropologia do Espaço" e "De casa em casa: sobre um encontro entre etnografia e cinema". E-mail: filomenasilvano@fcsh.unl.pt 
The concepts and methodologies of its very foundations were questioned and new lines of work materialized, reaching far beyond the limits of those more classic concepts of place. These approaches revealed, however, that when we come across logics of deterritorialization, the notion of place may reappear - although changed, due to distinct social, cultural and economical environments. Grounded upon ethnographic fieldwork in the Island of Pico (Azores), the text explores some of the innovations that were introduced in the Holy Ghost Festivals (Festas do Espírito Santo) - brought from the United States in the early twentieth century. Its main innovation had to do with the emergence of new characters, the "queens", who were crowned during the ritual, followed by the dressmakers, essential to the making of their costumes and cloaks. Focused on the manufacture of these cloaks, the text aims to show the way in which local material culture is created and transformed within a continuous transcontinental movement of people, rituals, things and techniques. In a transnational framework, the mobility of people can thus become objectified in these locally crafted things, as such deterritorialization itself becomes a part of the making of place.

Keywords: Place, transnationalism, material culture, Holy Ghost festivals, Island of Pico (Azores).

No início dos anos 1980, altura em que a geração de antropólogos da qual faço parte começou, em Portugal, a fazer investigação, o espaço existia para nós apenas como pano de fundo onde se passavam as coisas que considerávamos como assuntos antropológicos. A necessidade de delimitar espacialmente os terrenos de investigação fazia com que a ideia de lugar se impusesse, sem que no entanto sentíssemos necessidade de a trabalhar e, ainda menos, de a desmontar. Foi o confronto com o mundo real - onde o início da globalização se manifestava sob a forma de mobilidades de vários tipos - e o aparecimento de uma literatura crítica a que se convencionou chamar antropologia pós-moderna (de origem americana), que nos foram conduzindo, nas décadas seguintes, pelos caminhos da desmontagem da noção de lugar. Essa abordagem crítica fez-se, no entanto, sem que o espaço existisse como um objecto de estudo antropológico autónomo.

$\mathrm{O}$ que estava em causa eram sobretudo os modos de fazer antropologia. Nessa altura partia-se do pressuposto de que existia uma correspondência entre cultura e lugar e questioná-los implicava pensar também a questão espacial: um "terreno" era percepcionado como um espaço delimitado onde vivia uma população cuja cultura o antropólogo estudava (era a esse espaço que correspondia a noção de lugar - na formulação de Marc Augé em 1992 de "lugar antropológico"). Como a correspondência entre cultura e lugar estava, de forma muito evidente, a deixar de dar conta do real, tornava-se necessário encontrar formas de estudar a cultura, permitindo que a libertassem das amarras da localização. Nesse contexto de reformulação epistemológica da disciplina, a noção de lugar foi posta em causa, tendo as propostas de deslocalização da etnografia - que estavam inseridas numa reformulação mais vasta que envolvia também questões de ordem conceptual - conduzido a uma reflecção específica sobre o estatuto do espaço na Antropologia. 
O início da construção, no interior da Antropologia, de um campo dedicado ao estudo do espaço (autonomizando-o enquanto objecto de trabalho) deveu-se à academia francesa (que se mantinha então alheia às discussões que tinham lugar em língua inglesa), onde um contexto intelectual transdisciplinar interligou, a partir dos anos 1970, o trabalho de alguns arquitectos, urbanistas, sociólogos e antropólogos interessados em refazer as suas próprias disciplinas. A obra Anthropologie de l'Espace, publicada em 1983 por Françoise Paul Lévy e Marion Segaud, deu visibilidade a um novo campo disciplinar que, a partir daí, se foi afirmando, sobretudo nas academias do Sul da Europa. Duas décadas depois, nos EUA, mais uma vez num contexto de trabalho transdisciplinar, Setha Low e Lawrence-Zúñiga (2003) publicaram uma segunda obra, denominada The Anthropology of space and place, locating culture, que veio dar visibilidade ao mesmo campo disciplinar, inserindo-o desta vez no contexto académico anglo-saxónico onde se iniciaram as discussões relativas à deslocalização da etnografia ${ }^{i}$.

O facto, sempre reconhecido pela Antropologia, de todas as práticas culturais serem localizadas no espaço, passou a dar existência a um campo de estudo que propõe colocar o próprio espaço no centro dos seus interesses. Paradoxalmente - ou não! - o novo campo de estudo construiu-se em articulação com a desmontagem crítica da premissa que o legitimou, que afirma que o espaço tem um papel essencial na construção das identidades culturais. Na realidade, a associação entre espaço e identidade manteve-se, mas viu-se obrigada a uma reformulação que acompanhasse, por um lado as transformações do mundo, e, por outro, as da própria disciplina e do seu património metodológico e conceptual (as noções de cultura e de identidade sofreram, tal como a de lugar, uma revisão crítica que as afastou das formulações mais delimitativas). De entre as muitas propostas de trabalho que tentaram contribuir para essa reformulação, há uma que, a meu ver, se destaca, tendo-se revelado útil para o trabalho posterior de outros investigadores: para a formular, Appadurai (1997) propôs o neologismo ethnoscape.

Appadurai participou, durante uma década, nas discussões relativas à associação entre cultura e lugar (Appadurai, 1988a, 1988b; Gupta e Ferguson, 1992, 1997a, 1997b; Marcus, 1995a, 1995b, 1997; Clifford, 1997). Em 1997, quando a discussão epistemológica começou a traduzir-se em novas práticas etnográficas, avançou com a noção de ethnoscape para pensar algumas das novas formas de existência dos homens no espaço (aeroportos, meios de transporte, campos de refugiados, bairros de emigrantes...). A sua formulação pretendeu responder a questões que se colocavam em dois campos diferenciados. O primeiro, a que podemos chamar epistemológico, dizia respeito à questão da representação antropológica da cultura e do social. A desmontagem da ideia de nativo, associada à de lugar, levou Appadurai (tal como outros autores) a apelar para uma desterritorialização da observação e do olhar. O segundo dizia respeito às transformações que afectam as sociedades, os territórios e as formas de reprodução cultural dos grupos identitários no mundo contemporâneo. Dito de outro modo, às transformações reais com que a etnografia se confrontava. Estas reclamavam uma aproximação a visões mais flexíveis do espaço do que a ideia de lugar, visões mais próximas da ideia de fronteira, que passa a ser pensada não apenas como uma linha que separa espaços estáveis, mas como um espaço intermédio, deslizante, poroso. 
Uma só verdade diz respeito à relação entre espaço, estabilidade e reprodução cultural. Há uma necessidade urgente de focalizar as dinâmicas culturais naquilo a que hoje se chama desterritorialização (Appadurai, 1997, in Silvano, 2012).

A proposta de trabalho de Appadurai implicou ainda uma aproximação aos denominados "estudos culturais" que, segundo ele, se justifica pelo facto de a imaginação ter adquirido um novo e singular poder na vida social.

Os termos da negociação entre vidas imaginadas e mundos desterritorializados são complexos e não podem seguramente ser capturados apenas pelas estratégias localizadas da etnografia tradicional. O que um novo tipo de etnografia pode fazer é capturar o impacto da desterritorialização nos recursos imaginativos das experiências vividas localmente (Idem).

Nos últimos anos os antropólogos têm tentado ensaiar formas concretas de responder aos desafios epistemológicos formulados durante as décadas de 1980 e de 1990. No meu caso particular, tentei, num primeiro momento ${ }^{\text {ii }}$, desterritorializar a etnografia acompanhando emigrantes portugueses nos percursos anuais entre as suas várias casas situadas em França e em Portugal (Silvano, 1997, 2002, 2011). Com essa experiência percebi que as várias casas em que as pessoas vivem se interpenetram, não só porque são habitadas pelas mesmas pessoas, mas também porque há objectos que circulam entre elas: as coisas transportam memórias de outros lugares, permitindo que os espaços ausentes se tornem noutros lugares, presentes. A porosidade e o deslize das ethnoscape de Appadurai manifestam-se muitas vezes através de materialidades deslocadas (as figuras dos santos padroeiros transmontanos protegem as casas de Paris, tal como os utensílios domésticos parisienses asseguram, em Trás-os-Montes, a manutenção das práticas alimentares parisienses). Essa constatação aproximou-me dos estudos de cultura material e levou-me a associar as interrogações relativas ao espaço àquelas que se referem aos objectos. Nesse sentido tentei, num segundo momento, através de uma etnografia desta vez localizada, perceber como é que a cultura material local se constrói e se transforma no interior de um movimento transnacional constante de pessoas, rituais, coisas e técnicas ${ }^{\text {iii }}$. Dela farei aqui uma pequena apresentação, tentando demonstrar que a mobilidade das pessoas (mais concretamente a emigração transcontinental) se pode "objectificar" (Miller, 1987) em coisas que são feitas localmente, participando assim a desterritorialização da construção do lugar. Como defendem vários autores (Olwig, 1997; Mapril, 2011; Silvano e Tamaso, 2012), a figura do lugar, uma vez pensada no interior de uma lógica transnacional, acaba por reaparecer (embora obviamente transmutada, visto construir-se no interior de outras lógicas sociais, culturais e económicas).

\section{CULTURA MATERIAL E CONSTRUÇÃO DO LUGAR}

As festas do Divino Espírito Santo têm uma grande importância na vida social e cultural do arquipélago dos Açores, onde estão presentes, segundo documentação histórica, desde o século XVI. Ao longo do século XX foram também organizadas por comunidades de emigrantes açorianos em vários lugares do continente americano (nos Estados Unidos 
da América e no Canadá). Num movimento transnacional contínuo as festas foram-se transformando e hoje as componentes do ritual não são as mesmas em todas as ilhas do arquipélago. No caso da Ilha do Pico - onde localizei a minha etnografia - inovações provenientes dos Estados Unidos no início do século XX foram integradas nalgumas festas, tornando-se entretanto factores de diferenciação identitária significativos.

Se observarmos o conjunto do ritual, as festas - que consistem numa série de cerimónias em honra do Espírito Santo (aí representado por coroas de prata) - têm, no Pico e noutras ilhas dos Açores, uma organização semelhante. Em cada festa há um protagonista central, o "mordomo", que deve pertencer a uma "irmandade" (instituição dedicada à sua organização). O ritual inclui uma série de celebrações religiosas (procissões, rezas, missas), sendo a coroação do mordomo, durante uma missa, o momento mais importante. Realizam-se também grandes refeições e são distribuídos alimentos (pão, pão doce, carne) a um número significativo de pessoas. A principal inovação, introduzida por emigrantes vindos dos EUA nalguns lugares da Ilha do Pico, consistiu na coroação de jovens raparigas - as "rainhas" ou queens - que se tornaram assim nos personagens centrais de todo o ritual. A introdução das rainhas deslocou o foco do ritual dos homens para as jovens raparigas. Estes novos personagens foram secundados pelas costureiras, necessárias para a confecção dos seus trajes (fig. 1).

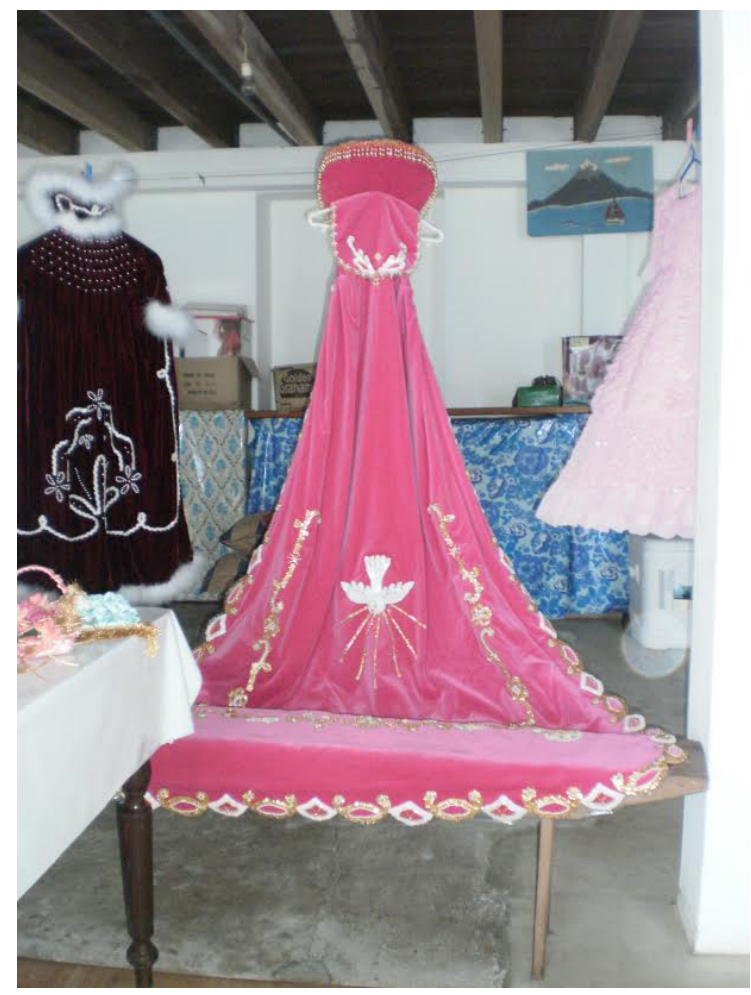

Fig. 1 - Mantos e vestido das rainhas.

Fig. 1 - The queens' robes and dresses. 
Emily Cabral, a primeira rainha (queen) que participou, em 1935, numa festa ocorrida nos Açores, era filha de um emigrante que havia feito fortuna em San Diego, nos EUA. A sua família introduziu assim, no lugar de Santa $\mathrm{Cruz}^{\mathrm{iv}}$, uma inovação cultural que a comunidade local rapidamente adoptou e que aí se reproduziu até aos nossos dias. Uma fotografia exposta no salão da irmandade da Segunda-feira (uma das duas instituições locais que organiza as festas), mostra Emily Cabral trajada com um vestido comprido e um longo manto debruado a arminho, em que sobressai uma gola que sobe por detrás do pescoço. Esse primeiro traje, trazido dos EUA para reproduzir uma prática ritual aí inventada por emigrantes açorianos na primeira metade do século XX, foi o ponto de partida para um duplo processo de inovação e de fixação da cultura material local. Ao longo do século XX os trânsitos entre a América e os Açores foram constantes; as pessoas, as roupas e os materiais fizeram viagens e foi no interior desse movimento que a cultura material associada às festas se reproduziu e se transformou - tanto nos Açores, como no Continente Americanov. Depois da sua introdução em 1935, a personagem das rainhas tornou-se num dos traços distintivos do ritual das festas da Freguesia das Ribeiras. Os mantos do Pico são, nesse sentido, peças de cultura material que "objectificam" (Miller, 1987) localmente o transnacionalismo que marca a vida da comunidade.

As duas peças centrais daquilo a que podemos chamar o "traje das rainhas" - o vestido e o manto - reproduzem ainda hoje duas das características dos primeiros exemplares vindos dos EUA: os vestidos são quase sempre brancos e o manto, a peça principal, tem uma gola que sobe por trás do pescoço (localmente chamada “cabeção"). É a manutenção dessas duas características que sustenta a ideia da existência de um "traje das rainhas"vi, pois apesar da diversidade há uma recorrência, que permite identificar um "traje ritual". Mas a presença dessas duas características não quer dizer que tenha havido uma simples lógica de reprodução de um artefacto (no sentido de um conjunto estável que integra um saber fazer, materiais e uma forma ${ }^{\text {vii }}$. Provavelmente, porque em Santa Cruz não havia nem os saberes artesanais nem os materiais que poderiam ter dado existência ao artefacto inventado nos EUA (pressupondo que nos EUA pudéssemos falar de reprodução de um artefacto, coisa da qual não estou certa). Consequentemente, as coisas fizeram-se sobretudo com os meios existentes no local. O modus operandi do "bricoleur", bem identificado por Lévi-Strauss em 1962, é por isso um bom ponto de partida para a leitura dos nossos dados etnográficos ${ }^{\text {viii. }}$. Podemos ainda acrescentar-lhe a proposta de Tim Ingold que, no que diz respeito à tentativa de ultrapassar o dualismo pessoa/materialidade, valoriza o papel da relação do homem com a matéria e o meio envolvente, em detrimento do papel dos supostos modelos intelectuais de partida.

(...) Les formes que les hommes construisent, dans leur imagination ou dans la réalité, surgissent au cours même de leurs activités, dans les contextes relationnels spécifiques de leur engagement pratique avec leurs environnements. La construction, dès lors, ne peut être comprise comme un simple processus transcrivant le modèle préexistant d'un produit final à un substrat matériel brut. (Ingold, 2013: 173) 
Quando Emily Cabral apareceu, vestida como uma rainha para inaugurar uma nova prática religiosa, ninguém na ilha tinha visto traje semelhante. Dois anos mais tarde, D. Berta, uma senhora que festejou os seus noventa anos nas festas de 2012, foi também coroada vestida com um manto de cetim azul debruado a arminho branco, bordado com pedrarias e ornamentado com uma gola levantada atrás do pescoço. Do modelo de Emily Cabral, D. Berta guardou o debrum de arminho e a gola levantada. Esta, que como referi se tornou num dos elementos obrigatórios do traje, é, desde o seu aparecimento, a peça que mais pôs à prova as capacidades das costureiras do Pico e das suas auxiliares (fig. 2). Interrogar um pouco o seu percurso ensina-nos coisas significativas sobre as maneiras de fazer localmente um objecto cuja origem se encontra no exterior.

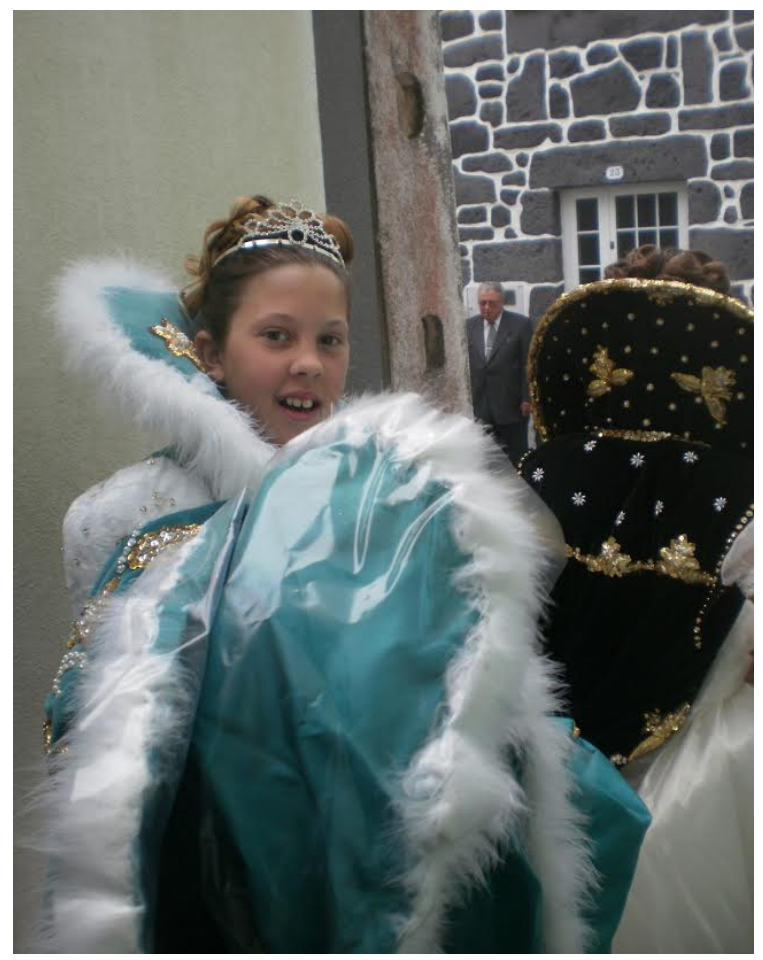

Fig. 2 - Rainhas com o seu traje.

Fig. 2 - Queens in costume.

Não conheço as soluções técnicas encontradas para dar, na América, uma existência material aos mantos, mas sei que quando as costureiras do Pico quiseram reproduzir os cabeções não tinham nem o saber fazer artesanal nem os materiais apropriados. Uma costureira que fez mantos na primeira metade do século XX tinha trabalhado com um alfaiate e tinha por isso conhecimentos técnicos relativos à utilização de entretelas. A memória oral refere essa mulher como sendo aquela que encontrou uma primeira solução para fazer o cabeção: utilizou como entretela as telas das velas dos barcos 
e montou a gola com esticadores de cortinas. Como um bricoleur, fez a sua gola com os materiais disponíveis no lugar. Desde aí, cada costureira imagina o seu cabeção e, partindo das soluções técnicas encontradas pela primeira costureira, encontra formas de o "fazer existir" (Latour, 2010). Cabe ainda dizer que a feitura dos mantos insere-se num contexto de "trabalho" excepcional: na maioria dos casos, os mantos e os vestidos são fabricados, sob a orientação das costureiras, por pessoas que não são da profissão e que pertencem à família da rainha ou ao seu círculo de relações. Mães, avós, e mesmo os pais, são convocados sempre que necessário: um dos mantos mais emblemáticos do lugar de Santa Cruz tem um cabeção cujo interior, de metal, foi feito pelo pai da rainha que é bate-chapas de profissão.

Durante quase um século houve fluxos contínuos de pessoas, técnicas e materiais que acompanharam a feitura dos trajes. Nesses fluxos houve materiais que vieram dos EUA e que foram utilizados para fazer os cabeções - por exemplo entretelas e esticadores - mas trata-se de uma peça que, na maioria dos casos, foi feita com materiais locais. Essa empatia com a matéria (Kuchler e Were, 2009) tem a particularidade de ser construída no interior de uma empatia do gesto: as costureiras manipularam as telas, em conjunto com os pescadores, como manipularam o metal, em conjunto com bate-chapas. Como Inglod (2013) propõe, a cultura é também essa co-presença dos corpos que, na partilha do gesto, aprendem e inventam técnicas e coisas. A forma de certos objectos deve ser situada no interior de processos de mediação que se desenvolvem em circunstâncias interculturais e interpessoais complexas (Myers, 2004) ${ }^{\mathrm{ix}}$. Os mantos do Pico são um desses casos, implicando as circunstâncias, de formas diversas, dois continentes.

Podemos perguntar-nos se, como resultado dessas circunstâncias interculturais e interpessoais complexas, surgiu no Pico um estilo de mantos das rainhas das festas do Espírito Santo. Se tomarmos por referência a definição de Layton (1991), segundo a qual um estilo se refere às qualidades formais de uma obra e se traduz na presença de certos temas e na regularidade de formas usadas para os representar e para os organizar num conjunto, penso que podemos falar de um estilo: sobre a forma fixa do manto um longo rectângulo com uma gola - organizam-se, ao longo das bordas, motivos decorativos, e, no meio ou nos ângulos, são colocadas imagens da iconografia do Espírito Santo (pombas, coroas, os sete Dons). Mas é necessário conceber o estilo mais como algo que enquadra a acção (e que portanto permite a introdução de variações, como refere Gell (1998)) do que como uma prescrição de um modelo. Face a uma inovação vinda do exterior as costureiras do Pico souberam inventar um estilo e, nesse sentido, contribuíram para a fixação de uma componente da cultura material da ilha. Hoje, tanto as novas componentes do ritual, como as novas componentes da cultura material a elas associadas, integram as características distintivas da identidade local da Ilha do Pico. O Museu dos Baleeiros organizou uma primeira exposição de mantos em homenagem a Maria de Lurdes Costa, a costureira mais talentosa da ilha, e a partir desse acontecimento o valor simbólico dos mantos expostos - que já era muito significativo - viu ser-lhe acrescentada uma nova componente patrimonial. É expectável que 
num contexto futuro de turistificação os mantos do Pico - cuja história está, desde a sua origem, ancorada na mobilidade transcontinental da sua população - se venham a tornar numa componente do património local que será mostrada a visitantes à procura de uma qualquer "autenticidade" perdida numa ilha no meio do Oceano.

\section{BIBLIOGRAFIA}

Appadurai, A. (1997). Modernity at large. Minneapolis: University of Minnesota Press.

Appadurai, A. (1988). Introduction: Place and voice in anthropological theory. Cultural Anthropology, 3, 16-20.

Appadurai, A (1988b). Putting Hierarchy in Its Place. Cultural Anthropology, 3, 36-49

Augé, M. (1992). Non-Lieux : introduction à une anthropologie de la surmodernité. Paris: Seuil.

Clifford, J. (1997). Routes, travel and translation in the late twentieth century. Cambridge-Massachusetts-London: Harvard University Press.

Gell, A. (1998). Art and Agency - an anthropological theory. Oxford: Clarendon Press.

Gupta, A. \& Ferguson, J. (1997a). Discipline and practice: "The field" as site, method, and location in anthropology. In A. Gupta \& J. Ferguson (org.), Anthropological Locations - boundaries and grounds of a field science (pp. 1-46). Berkeley, Los Angeles, London: University of California Press.

Gupta, A. \& Ferguson, J. (1997b). Culture, power, place: Ethnography at the end of an era. In A. Gupta \& J. Ferguson (org.), Culture, Power and Place. Explorations in Critical Anthropology (pp. 1-29). Duke: Duke University Press.

Gupta, A. \& Ferguson, J. (1992). Beyond "Culture": Space, Identity, and the Politics of Difference. Cultural Anthropology, 7, 6-23.

Hansen, K. T. (2004). The world in dress: anthropological perspectives on clothing, fashion, and culture. Annual Review of Anthropology, 33, 369-392.

Ingold, T. (2013). Marcher avec les dragons. Zones Bruxelles: Sensibles.

Kuchler, S. \& Were, G. (2009). Empathie avec la matière - Comment repenser la nature de l'action technique. Techniques \& Culture, 52-53, 190-211.

Latour, B. (2010). Prendre le pli des techniques. Réseaux, $163,15-31$
Layton, R. (1991). A Antropologia da arte. Lisboa: Edições 70.

Leal, J. (2011). Azorean Identity in Brazil and the United States: Arguments about History, Culture and Transnational Connections. Dartmouth MA: Center for Portuguese Studies and Culture. Dartmouth: University of Massachusetts.

Leal, J. (2014). From California to the Azores. Come Back Travels of the Holy Ghost: Seminar "Ritual, Ethnicity, Transnationalism, Holy Ghost Festivals in North America". Lisboa: CRIA (UNL).

Lévi-Strauss, C. (1962). La Pensée sauvage. Paris: Plon.

Low, S. M. \& Lawrence-Zúñiga, D. (2003). The Anthropology of space and place, locating culture. Malden/Oxford/Carlton/Berlin: Blackwell.

Mapril, J. (2011). Islão e transnacionalism - uma etnografia entre Portugal e o Bangladeche. Lisboa: Imprensa de Ciências Sociais.

Marcus, G. (1989). Imagining the whole: ethnography's contemporary efforts to situate itself. Critique of Anthropology, 9 (3), 7-30.

Marcus, G. (1997). Some strategies for the design of contemporary fieldwork projects: advice to new students. Ethnologia, 6-8, 55-64.

Miller, D. (1987). Material culture and mass consumption. Oxford: Blackwell.

Myers, F. (2004). Social agency and the cultural value(s) of the art object. Journal of Material Culture, 9 (2), 205-213

Olwig, K. (1997). Cultural sites: sustaining a home in a deterritorialized word. In O. Karen \& H. Kristen (Eds.), Siting Culture: The shifting Anthropological object (pp. 17-39). Londres: Routledge.

Paul-Lévy, F. \& Segaud, M. (1983). Anthropologie de lespace. Paris: Centre Georges Pompidou/CCI.

Rodman, M. (1992). Empowering Place: Multilocality and Multivocality. American Anthropologist, 94 (3), 640-656.

Silvano, F. (1997). Vidas em trânsito. Ethnologia, 6-8, 163-174. 
Silvano, F. (2002). José e Jacinta nem sempre vivem nos mesmos lugares: reflexões em torno de uma experiência de etnografia multi-situada. Ethnologia, 12-14, 53-79.

Silvano, F, (2011). De casa em casa: sobre um encontro entre etnografia e cinema. Caldas da Rainha: Palavrão.

Silvano, F. (2012). Antropologia do espaço. Lisboa: Assírio \& Alvim.
Silvano, F. (2014). Les petites reines et leurs couturières Hansen, tes reines et do por Jo Ottawa.tlantiques des objets et du savoir-faire, ram secundados faite sens l' Pico a Sdo por Jo: entre l'Amérique et les Açores, les parcours transatlantiques des objets et du savoir-faire: Colloque international de l'ACSALF. Ottawa: Université d'Ottawa.

Silvano, F. \& Tamaso, I. (2013). Dossier "Antropologia do Lugar". Sociedade e Cultura, 16( 1), Goiás.

i Para uma abordagem mais completa deste percurso, ver Silvano (2012).

ii Refiro-me ao acompanhamento das filmagens dos documentários de João Pedro Rodrigues "Esta é a minha casa" e "Viagem à expo" (em 1997 e 1998 respectivamente). Ambos os filmes foram editados com o ensaio "De casa em casa: sobre um encontro entre etnografia e cinema" (Silvano, 2011).

iii Refiro-me à minha participação no projecto "Ritual, Ethnicity and Transnationalism: Holy Ghost Festivals in North America - (PTDC/CS-ANT/100037/2008)”, coordenado por João Leal. A etnografia mencionada realizou-se na Ilha do Pico (Freguesia das Ribeiras) e centrou-se na observação, durante as festas do Espírito Santo do ano de 2012, do trabalho das costureiras responsáveis pela feitura dos trajes das "rainhas", personagens centrais das referidas festas. Foi realizada na companhia de João Leal, que generosamente me transmitiu a informação mais geral sobre as festas necessária à elaboração do meu argumento (Leal, 2011, 2014).

iv Santa Cruz pertence à freguesia de Ribeiras e ao concelho das Lajes do Pico.

v Sobre o contexto transnacional mais geral - onde se integram a Freguesia das Ribeiras e San Diego - ver Leal (2014). Para uma versão mais completa do meu argumento ver Silvano (2014).

vi Utilizo a palavra traje no sentido que dá Hansen (2004: 371) à palavra inglesa "costume" (por oposição às palavras "dress" e "clothes"): (...) costume used in dress scholarship for ensembles coordinated for masquerades, theatrical parts, dress from distinct historical periods, and native, indigenous clothing styles.

vii "L' artefact est donc la cristallisation d'une activité à l'intérieur d’un champ relationnel, et les régularités de ses formes correspondent aux régularités du mouvement qui le façonne" (Ingold, 2013: 215).

viii "Son univers instrumental est clos, et la règle de son jeu est de toujours s'arranger avec les « moyens du bord ", c'est-à-dire un ensemble à chaque instant fini d'outils et de matériaux, hétéroclites au surplus, parce que la composition de l’ensemble n’est pas en rapport avec le projet du moment (...)" (Lévi-Stauss, 1962: 27).

ix "Here, the form of objects is addressed analytically not simply as an expression of a universal or even culturally specific aesthetics, but as situated in the mediation of complex intercultural and interpersonal political circumstances." (Myers, 2004: 206). 